\title{
Inquiry-based professional learning in the practicum: Potential and shortcomings
}

\author{
Flávia Vieira*, Maria Assunção Flores, José Luís Coelho da Silva, Maria Judite Almeida, \\ Teresa Vilaça
}

University of Minho, Portugal

\section{H I G H L I G H T S}

- Teacher inquiry is both necessary and controversial in ITE programmes.

- The value and shortcomings of an inquiry-based practicum model are examined.

- Participants' perceptions and evidence from practicum reports are consistent with the model's rationale.

- Practicum promotes inquiry competences, multifaceted professional knowledge, and a transformative vision of education.

- Constraints to inquiry relate to contextual variables but also to prevailing academic and school cultures.

\section{A R T I C L E I N F O}

\section{Article history:}

Received 4 May 2020

Received in revised form

20 June 2021

Accepted 20 June 2021

Available online $\mathrm{xxx}$

\section{Keywords:}

Initial teacher education

Practicum

Inquiry

Professional learning

\begin{abstract}
A B S T R A C T
The paper presents a study conducted at the authors' institution to evaluate the potential and shortcomings of an inquiry-based practicum model in post-Bologna initial teacher education master programs. Data was collected through survey questionnaires to practicum participants and the analysis of student teachers' practicum reports. Results show that the participants' views (perceived quality) and evidence from practicum reports (inferred quality) are globally aligned with the model's rationale (intended quality). The model promotes inquiry competences, multifaceted professional knowledge, and a transformative vision of education. Shortcomings of and constraints to inquiry are discussed, and future directions for enhancing it are presented.
\end{abstract}

() 2021 Elsevier Ltd. All rights reserved.

\section{Introduction}

European policies on teacher education have stressed the central role of reflection and inquiry for ongoing professional development (Council of the European Union, 2007; European Commission, 2015). Inquiry into teaching favors a notion of teaching as a 'discipline' (Loughran, 2009; Martin \& Russell, 2009) and as an 'epistemic engine', that is, an activity capable of producing practical knowledge (Loughran, 2009, p. 200).

In its various forms, namely action research, teacher inquiry has long been recommended and used to foster a critical understanding of professional contexts and to support reflective practice, educational change, and the development of self-improving educational systems (Atweh, Kemmis, \& Weeks, 1998; Bell, 2001; Burnaford, 2001; Burnaford, Fischer, \& Hobson, 2001; Carr \& Kemmis, 1986; Clarke \& Erickson, 2003a, 2003b; Loughran, 2003; McNiff, 2013). Teachers' research literacy, globally defined as "the ability to judiciously use, apply and develop research as an integral part of one's teaching" (Evans, Waring, \& Christodoulou, 2017, p. 404), has been considered an important aspect of teacher professionalism and a goal of initial teacher education (ITE) programs (Bullock, 2016). However, the nature and purposes of inquiry-based approaches in ITE programs vary considerably (Vaughan \& Burnaford, 2016), and their value is often contested since they

\footnotetext{
* Corresponding author.

E-mail addresses: flaviav@ie.uminho.pt (F. Vieira), aflores@ie.uminho.pt (M.A. Flores), zeluis@ie.uminho.pt (J.L. Coelho da Silva), juditealmeida@bio. uminho.pt (M.J. Almeida), tvilaca@ie.uminho.pt (T. Vilaça).
} 
entail a deviation from established teacher education rationales and forms of inquiry. This paper looks at the potential and shortcomings of an inquiry-based model used in the practicum (field experiences) of ITE programs at the authors' university, ${ }^{1}$ seeking to contribute to the debate on the role of inquiry for professional learning.

The model was designed in 2007 as a result of the Bologna Process, when ITE masters in teaching were created in Portugal. ${ }^{2}$ Pre-Bologna ITE programs were permeated by a general tendency towards the academization of learning (Canário, 2002; Estrela, Esteves, \& Rodrigues, 2002; Formosinho, 2009). Students learnt about progressive educational theories and methodologies, but no professional learning models were in place to support innovation in practicum settings. Student teachers often complied with established school cultures as a form of socialization into the profession, and inquiry-based teaching was rare. Lesson observation and supervisory conferences were the main (often the only) teacher education strategies, and student teachers usually produced a practicum dossier that compiled their work with no apparent purpose other than final assessment.

The Bologna reform offered an opportunity to reshape this situation. New ITE policies put greater emphasis on educational research and the development of reflective professionals. As pointed out by Campos (2010), this emphasis was in tune with European policy recommendations, yet it also represented a great challenge for HEIs. There has been no consensus regarding the nature and role of research in ITE programs, and different paths were followed in higher education institutions (HEIs), such as the creation of research course units, the development of inquiryoriented field experiences, or the inclusion of theoretical essays in practicum reports.

At the authors' institution, the decision was made to bring teaching and research together by designing a cross-disciplinary practicum model that puts the development of inquiry-based teaching projects at the center of professional learning. The model applies to all masters in teaching, entailing the adoption of a transformative vision of education and seeking to counteract the divide between teaching and research, and between theory and practice (Schön, 1987; Zeichner, 2010). Its implementation brought about substantial conceptual and methodological changes, instigating the development of local studies carried out by teacher educators/supervisors (including the authors) to investigate its impact. Results based on focus group interviews and the analysis of practicum reports have shown the positive impact of the model on promoting reflective, learner-centered teaching, but also the existence of tensions and ambiguities concerning the teachingresearch nexus in professional learning (Flores, 2018; Flores, Vieira, Silva, \& Almeida, 2016; Vieira, Flores, Silva, \& Almeida,

\footnotetext{
1 The authors' university is a teaching and research public institution with 11 Faculties. The Institute of Education is responsible for ITE programs, with the collaboration of other Faculties. All programs include a period of initiation to professional practice in local schools (practicum).

2 The Bologna Process is an intergovernmental higher education reform process that includes 49 European countries. It was launched in 1998-1999 to enhance the quality and recognition of European higher education systems and to improve the conditions for exchange and collaboration within Europe and internationally, leading to the creation of the European Higher Education Area (EHEA) in 2010 (https://www.ehea.info/). In our country, the reform was initiated in 2006 and it involved a substantial change in ITE. Masters in teaching were created in accordance with Decree-Law No. 43/2007, replacing previous four to five-year bachelor degrees by a consecutive, two-stage model: a three-year bachelor degree on a specific subject, followed by a master degree in teaching with 90 or 120 ECTS (three or four semesters). Credits are calculated according to the European Credit Transfer and Accumulation System (ECTS) and one credit corresponds to 27 or $28 \mathrm{~h}$ of student work.
}

2019). The need to further investigate the role of inquiry motivated the study reported here. It was conducted in 2019, 10 years after the implementation of the model, involving survey questionnaires to former practicum participants and the analysis of a larger sample of student teachers' practicum reports. The findings focus on the extent to which the model develops student teachers' competences for inquiry-based teaching, their professional knowledge, and a transformative vision of education. Potential constraints to and future directions for teacher inquiry are discussed with reference to academic research cultures, ITE programs, and school cultures.

\section{Inquiry-based teaching in initial teacher education}

In ITE programs, namely in practicum settings, inquiry may be understood as a key element in overcoming a technical and sometimes simplistic view of teaching, empowering student teachers to develop personal professional knowledge (Bullock, 2016; Loughran \& Menter, 2019). Inquiry-based teaching enhances their ability to analyze practice and make creative, contextsensitive decisions, thus preventing a technical rationality based on the application of research-based knowledge to instrumental problem solving (Schön, 1987).

From this perspective, educational theory is put at the service of pedagogy, inspiring and supporting inquiry rather than determining it. As Carr (2006) pointed out, since educational theories are historically embedded and there are no epistemological foundations that guarantee the truth of theoretical knowledge, the legitimacy of theory to determine practice must be questioned. This means that theories are only relevant for professional learning insofar as they resonate with student teachers' experience and help them understand and transform their professional understandings and practice. As suggested by the author, "educational theory does not cause educational change but may be appropriated in the cause of educational change" (Carr, 2006, p. 155).

Since education is a value-laden enterprise in which human interests are crucial, teacher inquiry towards educational change has an ethical dimension regarding the visions of education it pursues (Bell, 2001). From a democratic perspective, inquiry should promote a transformative vision of education whereby teachers question and reshape existing cultures of teaching and learning in schools. This transformative vision entails a conception of teachers as change agents both at the classroom and school level (van der Heijden, Geldens, Beijaard, \& Popeijus, 2015). Inquiry-based innovation may foster dialogic and learner-centered pedagogies, thus enhancing the humanization of learning, teaching and professional development as relational, people-centered practices (Ellis, SoutoManning, \& Turvey, 2019, p. 7). It can further become a path to professional empowerment and social transformation, by promoting teachers' critical awareness of factors that constrain democracy in educational settings and enhancing their role as selfdetermined, change-oriented educators (Kemmis \& Wilkinson, 1998; Kincheloe, 2003; Zeichner, 2009).

Despite the potential benefits of teacher inquiry in ITE programs, its implementation counteracts a long-standing academic tradition that undervalues its legitimacy as a valid source of knowledge (Bell, 2001). Diverse positions regarding its status have been put forward. For example, Tatto (2020, p. 145) makes a distinction between research and good practice based on inquirybased teaching, whereas Smith (2018, p. 32) claims that denying the label 'research' to inquiry-based teaching will hamper the expansion of educational research and reinforce the false notion that only academic researchers can produce 'expert' findings about teaching.

The use of inquiry in teaching and in teacher education entails a 
diversity of understandings of teacher research (Bell, 2001; Cain, 2015; Flores, 2018; Flores et al., 2016; Matheson \& Edwards, 2016). Its contested and complex nature has been documented in studies that highlighted teacher candidates' diverse understandings of and responses to research-based learning (Puustinen, Santti, Koski, \& Tammi, 2018; vanKatwijk, Berry, Jansen, \& vanVeen, 2020), as well as teacher educators' diverse understandings and experiences of research and how this may influence their teaching approaches (Brew \& Saunders, 2020; Cao, Postareff, Lindblom-Ylanne, \& Toom, 2019). Ultimately, the adoption of inquiry as a teacher education strategy appears to rely on teacher educators' views of teaching and learning to teach. As Zeichner and Conklin (2008, p. 173) suggested, what counts as quality in teacher education pedagogies depends not only on research evidence, but also on moral and ethical considerations regarding the role of teachers as either decision makers who question school policies or mere executors of pre-defined scripts.

A broad and inclusive perspective on the role of research in teacher education was proposed in the BERA-RSA report published in 2014, based on information and evidence gained through commissioned papers produced by a range of internationally recognized experts. Four ways in which research can contribute to teacher education were identified: i) the content of teacher education is to be informed by research-based knowledge and scholarship; ii) research can be used to inform the design and structure of teacher education programs; iii) teachers and teacher educators can be equipped to engage with and be discerning consumers of research; iv) teachers and teacher educators may be equipped to conduct their own research, individually and collectively, to investigate the impact of particular interventions or to explore the positive and negative effects of educational practice (BERA-RSA, 2014, p. 5). This last aspect, which is often missing from student teachers' initiation to practice in ITE programs, is at the core of the practicum model described below.

\section{Moving towards inquiry-based teaching: a practicum model}

As a result of the Bologna reform in Portugal, previous four to five-year ITE bachelor degrees integrating subject-based and pedagogical training were replaced by a consecutive, two-stage model: a three-year bachelor degree on a specific subject (e.g., Languages, Mathematics ...), followed by a master degree in teaching with three or four semesters (90/120 ECTS), combining subject-based with pedagogical training. ${ }^{3}$ This means that students' pedagogical preparation is condensed in the master programs. In addition, although the practicum continues to be oneyear long as before (the last two semesters of all programs), it occurs in parallel with other course units and time for fieldwork was shortened in most cases.

Despite the reduction of time for pedagogical training and teaching practice, national regulations regarding the masters in teaching put higher demands than before on the quality of professional learning, namely by determining that the students' research literacy should be developed and that a practicum report should be produced to be defended publicly before an examining board as part of professional assessment.

\footnotetext{
3 Masters in teaching must integrate five training components: General Education (e.g., Curriculum Development, Psychology of Education), Teaching Subject (e.g., Languages, Mathematics), Specific Didactics (referring to the teaching subject), Professional Practice/Practicum with about one third of the total credits, and the cultural, social and ethical dimension of teaching, which is expected to be developed within the other training components.
}

The inquiry-based practicum model designed in 2007 at the authors' institution was largely inspired by a local supervision project that was developed from 1995 to 2007 by a small group of language supervisors, in which student teachers developed action research projects for promoting a pedagogy for autonomy in schools (Moreira \& Vieira, 2012; Vieira \& Moreira, 2008). Although action research can be developed in various ways and for different purposes, it was broadly understood as classroom-based inquiry undertaken by student teachers to understand and improve practice, involving cycles of planning-acting-observing-reflecting, and combining the development of research and practitioner competences (Vaughan \& Burnaford, 2016). Zwozdiak-Myers (2012) proposed a framework for teachers' reflective practice with nine dimensions that are expected to be present in student teachers' inquiry within our model: study their own teaching for personal improvement; systematically evaluate their own teaching through classroom research procedures; link theory with their own practice; question their personal theories and beliefs; consider alternative perspectives and possibilities; try out new strategies and ideas; maximize the learning potential of all their students; enhance the quality of their own teaching; and continue to improve their own teaching. From this perspective, student teachers' research literacy is developed at the service of pedagogy, in close connection with their views and aspirations regarding good educational practice (Burnaford, 2001).

Fig. 1 presents the overall organization of the model. Its main goal is to enhance reflective, learner-centered teaching, within a transformative vision of education based on humanistic and democratic values. The development of supervised inquiry-based teaching projects in schools is the overarching strategy to accomplish that goal.

Student teachers' projects are mentored by faculty supervisors and cooperating teachers at school, ${ }^{4}$ in whose classes student teachers teach a minimum of 24 hours. Projects must follow a set of guidelines listed in the practicum internal regulation and in the Practicum Dossier ${ }^{5}$ :

Adequacy to the contexts of practice - Knowledge and problematization of teaching contexts in order to design and develop action plans that are relevant in the face of situational variables.

Orientation towards practice - Definition of topics, objectives and action strategies that result from the observation and analysis of teaching and learning practices within the teaching area, and contribute to understanding and improving those practices.

Ethical and conceptual grounding - Grounding in up-to-date and relevant ethical and conceptual assumptions oriented towards the development of inclusive practices that are centered on learning and support educational success.

Research at the service of pedagogy - Use of pedagogical research strategies that support the understanding and improvement of teaching and learning practices.

Formative potential - Articulation between the project's objectives and the student teacher's professional development goals,

\footnotetext{
${ }^{4}$ Faculty supervisors are experts in didactics and supervision, and cooperating teachers are experienced schoolteachers appointed by school principals within cooperation protocols established every year between schools and the university.

5 This Dossier is organized by the general coordinator of the practicum (the first author until September 2019 and the last author since then). It integrates guidelines regarding the practicum model (rationale, goals and strategies), as well as proposals for supervisory work (e.g., instruments to support project design and analysis, lesson observation, portfolio analysis, report writing, and assessment).
} 


\begin{tabular}{|c|c|c|}
\hline \multicolumn{3}{|c|}{ RATIONALE } \\
\hline \multicolumn{3}{|c|}{$\begin{array}{l}\text { Inquiry-based professional development aimed at enhancing reflective, learner-centered teaching } \\
\text { within a transformative vision of education based on humanistic and democratic values }\end{array}$} \\
\hline \multicolumn{3}{|c|}{ PROJECT DEVELOPMENT: STAGES, SUPPORT, AND ASSESSMENT } \\
\hline Project Design & Project Implementation & $\begin{array}{c}\text { Project Report } \\
\text { (delivered after the practicum) }\end{array}$ \\
\hline $\begin{array}{l}\text { Context analysis } \\
\text { Literature review } \\
\text { Project proposal } \\
\text { Proposal approval }\end{array}$ & $\begin{array}{l}\text { Project development in one of the } \\
\text { cooperating teacher's classes } \\
\text { Inquiry into practice through } \\
\text { ongoing data collection } \& \text { analysis } \\
\text { Portfolio writing }\end{array}$ & $\begin{array}{l}\text { Systematization of inquiry } \\
\text { Report writing } \\
\text { (20 000 to } 25000 \text { words) } \\
\text { Public defense before an } \\
\text { examining board }\end{array}$ \\
\hline \multicolumn{2}{|c|}{$\begin{array}{l}\text { University-based seminars to support practice } \\
\text { Supervision conferences at school and university } \\
\text { Observation by cooperating teachers and faculty supervisors }\end{array}$} & Faculty supervisor support \\
\hline \multicolumn{2}{|c|}{$\begin{array}{l}\text { Formative and summative self/co-assessment of } \\
\text { participation in seminars and supervision conferences, } \\
\text { project proposal, classroom practice, and portfolio }(50 \%)\end{array}$} & $\begin{array}{l}\text { Assessment of project report by } \\
\text { examining board }(50 \%)\end{array}$ \\
\hline \multicolumn{3}{|c|}{ PRACTICUM SUPPORT \& COORDINATION } \\
\hline \multicolumn{3}{|c|}{$\begin{array}{l}\text { Dissemination of support materials (internal regulations and Practicum Dossier) } \\
\text { Initial training course ( } 25 \mathrm{~h} \text { ) on pedagogical supervision for cooperating teachers (every year) } \\
\text { Coordination meetings between the general coordinator of the practicum and program directors } \\
\text { Coordination meetings between program directors and practicum participants }\end{array}$} \\
\hline
\end{tabular}

Fig. 1. Overall organization of the practicum model.

within a view of professional practice that favors the development of reflection, self-direction, collaboration and creativity/ innovation skills.

(Regulation of the Masters in Teaching and Practicum Dossier, University of Minho, Institute of Education)

Dialogue and cooperation between faculty supervisors and cooperating teachers is of paramount importance to ensure that projects are conceptually sound, appropriate to contexts, and feasible in the time available. A training course for cooperating teachers is held at the beginning of every academic year to familiarize them with the practicum model, update their knowledge on reflective professional development and inquiry-based teaching, and enhance their collaboration in projects. Nevertheless, the course is not compulsory and faculty supervisors are expected to play a major role in guiding student teachers' inquiry, given their research experience.

Project design takes place during an extended period of context analysis, lesson observation and guided readings. There is a university-based seminar on pedagogical inquiry and project design, where student teachers discuss their project proposals and learn about methods for data collection and analysis. Project proposals are approved by the general coordinator of the practicum and program directors, on the basis of the guidelines presented above.

Each project is developed in one of the cooperating teacher's classes, involving the exploration of learner-centered strategies along with the collection and analysis of classroom data. For example, a student teacher of English in a primary school might explore a storytelling approach to promote children's citizenship competences, involving them in tasks that promote their awareness of how stories relate to their lived experience and convey visions of the world, and collecting data through dialogue and the analysis of learner performance and feedback on tasks. Projects are documented in a reflective portfolio, which is accompanied by cooperating teachers and supervisors, and in the final report, which is supervised by the faculty supervisor.

Reports are understood as professional narratives written in the first person, where student teachers present and analyze their project, integrating relevant theoretical input and evidence from practice. Report writing is intended to enhance critical thinking and the theorization of practice through the integration of experience, theory, and practical wisdom (Lunenberg \& Korthagen, 2009). The report is presented before an examining board that integrates the program director, the faculty supervisor, and one or two experts in the teaching field, usually from within the institution. All reports are available in the university's online repositorium, although not necessarily with open access as students may choose from a range of access possibilities.

Moving towards inquiry-based professional learning in the practicum has required the implementation of measures to ensure cross-program and university-school coordination, along with the development of local studies to investigate the formative value of the model. The evaluative case study reported below is the most recent study.

\section{The study: research questions and methods}

Case studies are studies of singularities carried out in natural settings, and evaluative case studies usually focus on the worthwhileness of a particular educational program, system or project, seeking to point out developments for subsequent policies and practices (Bassey, 1999). In order to appraise the potential and 
shortcomings of the practicum model 10 years after its implementation (2008/09 to 2017/18), an evaluative case study was conducted in 2019, using two methods of data collection - online survey questionnaires (to former student teachers, cooperating teachers and faculty supervisors) and the interpretative analysis of practicum reports. By focusing on the ITE programs where the authors work as teacher educators, the study illustrates a self-study approach to teacher education research (Loughran, 2007), whose major purpose was to investigate issues that are critical to the practicum model (the case) and point our directions for future developments. Those issues are expressed in the two research questions addressed in this paper:

- How does the model promote the development of competences for inquiry-based teaching?

- How does it promote the development of professional knowledge and a transformative vision of education?

An interpretative stance towards reality as a construct of the mind requires that educational phenomena be understood from multiple perspectives (Bassey, 1999). In seeking to answer the research questions, a multi-perspective approach was used by comparing the model's rationale regarding inquiry-based professional learning (intended quality), which informed the construction of the research instruments, with the participants' perceptions (perceived quality) and evidence from practicum reports (inferred quality). Methodological triangulation - survey and report analysis - and the triangulation of data from different types of participants - supervisors, cooperating teachers and student teachers - were used to mitigate bias and enhance the trustworthiness of results (Fuch, Fuch, \& Ness, 2018). However, since the survey samples are random and there is not a correspondence between the respondents and the reports analyzed, comparisons between groups and between perceptions and report evidence must be interpreted with caution, even though they provide relevant information for an overall evaluation of the model.

The confidentiality of data and the anonymity of participants were ensured at all stages of the study. Contacts with survey respondents were done through e-mail by the institutional practicum coordinator, with an explanation of the study and a link to the online survey questionnaires. The questionnaires integrated an Informed Consent Statement, and all the reports analyzed are available at the institutional online repositorium. However, in order to protect the student teachers' identities, the results were aggregated and no direct transcriptions were used for dissemination purposes. The study proposal was submitted to the University's Ethics Committee, and it was approved for "meeting the requirements demanded for good practices in human research, in compliance with the national and international rules which regulate research in social and human sciences" (Ethics Committee Report-CE. CSH 103/2018, January 24, 2019).

\subsection{Survey questionnaires and participants}

Two similar questionnaires were designed by the authors, one for supervisors and cooperating teachers, and the other one for former student teachers. They included a set of questions about the practicum model, based on its strategies and expected outcomes (intended quality). The survey questions were mostly closed, with six-point Likert scales (Importance and Evidence), collecting the participants' perceptions about the importance of the training strategies used to support inquiry, and the extent to which inquiry competences were evident in reports. No statistical procedures were used to assess the reliability and the validity of the questionnaires, since the items were designed in accordance with the specific features of the model being assessed, and both the authors and the respondents were familiar with it. Its assumptions, purposes and strategies are explicitly stated in supporting documents and thoroughly discussed with practicum participants. The context-bound nature of the survey items enhanced its descriptive validity as regards the relation between data collected and the focus of inquiry (Martella, Nelson, \& Marchand-Martella, 1999).

Descriptive statistical analysis was carried out for frequency, mode and median values. To calculate the mode and median values, the ordinal scales were converted into numeric scales from 1 (Not Important/Not Evident) to 5 (Very Important/Very Evident). The scale point No Opinion was coded as 0 . In section 5 , the tables with results integrate the survey items.

The survey was launched online in the beginning of 2019. It comprised the masters in teaching that were offered at that time, in a total of 17 programs, some of which were equivalent and had been previously readjusted with changes in designation. The programs concern different teaching fields, in some cases combining two or more of them - Early Childhood Education, Primary Education, Portuguese, Spanish, English, Science, Mathematics, Informatics, History, Geography, Philosophy, and Music. They prepare teachers for diverse school levels, from pre-school education to grade 12 in secondary education.

All the faculty supervisors working on those programs were surveyed $(\mathrm{n}=78$ ) since they are a stable group of staff. Cooperating teachers and student teachers vary over time, therefore the interval considered for the survey was the 5-year period prior to the study (2013/14-2017/18) so as to increase the reliability of their answers. All the cooperating teachers from those years were surveyed ( $\mathrm{n}=427$ ), as well as all the former student teachers who had submitted their final practicum report during that period $(n=548)$.

The questionnaires were answered by 34 supervisors $(43.6 \%$ of the group), 112 cooperating teachers (26.2\%) and 133 former student teachers $(24.3 \%)$, in a total of 279 respondents (26.5\% of the total sample) distributed across all the programs.

Some background information on the three groups was collected in the questionnaires. Most supervisors (94.2\%) and cooperating teachers (78.6\%) had 16 or more years of teaching experience. Table 1 indicates their experience of supervision, which was larger in the case of supervisors because of their institutional role. Previous training and research experience in the field of supervision was pointed out by most supervisors and nearly half of the cooperating teachers.

Table 2 shows that former student teachers came from 13 programs covering all teaching fields and concluded their practicum from 2013 to 2018. Approximately half of them had teaching experience before the practicum and taught while in the practicum, and the majority $(81.2 \%)$ had teaching experience after the practicum.

\subsection{Report analysis}

The interpretative analysis of practicum reports was initiated in 2012/13 for previous studies undertaken by a larger multidisciplinary team of teacher educators (including some of the present authors), and has been expanded over time as an ongoing task. Until the present study, a corpus of 44 reports concluded from 2011 to 2019 were analyzed amongst those that were published with open access in the institutional online repositorium. Although the sample is limited as compared to the total number of reports (around 100 are defended each year, although not all are available online), it illustrates the type of work undertaken in the practicum. To enhance the trustworthiness of results, reports were selected so as to cover different academic years and various teaching areas, levels and topics, as well as different supervisors and cooperating 
Table 1

Background information: supervisors $(\mathrm{n}=34)$ and cooperating teachers $(\mathrm{n}=112)$.

\begin{tabular}{|c|c|c|c|}
\hline & & Faculty Supervisors \% & Cooperating Teachers \% \\
\hline \multirow[t]{4}{*}{ Years of supervision in post-Bologna MAs in Teaching at the institution } & 1 & 0.0 & 27.7 \\
\hline & $2-3$ & 8.8 & 34.8 \\
\hline & $4-5$ & 8.8 & 15.2 \\
\hline & $5+$ & 82.4 & 22.3 \\
\hline \multirow[t]{4}{*}{ Number of practicum projects supervised } & 1 & 0.0 & 23.2 \\
\hline & $2-3$ & 8.8 & 32.1 \\
\hline & $4-5$ & 0.0 & 13.4 \\
\hline & $5+$ & 91.2 & 31.3 \\
\hline
\end{tabular}

Table 2

Background information: former student teachers $(n=133)$.

\begin{tabular}{|c|c|c|}
\hline & & $\%$ \\
\hline Teaching fields: & ECE & 10.5 \\
\hline Early Childhood Education (ECE) & $\mathrm{ECE} / \mathrm{PE}$ & 15.8 \\
\hline Primary Education (PE) & $\mathrm{PE} / \mathrm{P} / \mathrm{H} / \mathrm{G}$ & 2.4 \\
\hline Portuguese $(\mathrm{P})$ & $\mathrm{H} / \mathrm{G}$ & 0.8 \\
\hline Spanish (S) & $\mathrm{H}$ & 1.5 \\
\hline English (E) & $\mathrm{PE} / \mathrm{M} / \mathrm{Sc}$ & 8.3 \\
\hline History $(\mathrm{H})$ & Sc & 0.8 \\
\hline Geography (G) & $\mathrm{P} / \mathrm{S}$ & 7.5 \\
\hline Mathematics (M) & $\mathrm{E} / \mathrm{S}$ & 8.3 \\
\hline Science $(\mathrm{Sc})$ & $\mathrm{E}$ & 4.5 \\
\hline Informatics (I) & I & 9.8 \\
\hline Philosophy (Ph) & $\mathrm{Ph}$ & 1.5 \\
\hline Music (Mu) & $\mathrm{Mu}$ & 28.6 \\
\hline \multirow[t]{6}{*}{ Year when the practicum was completed } & 2013 & 2.3 \\
\hline & 2014 & 16.5 \\
\hline & 2015 & 13.5 \\
\hline & 2016 & 21.8 \\
\hline & 2017 & 19.5 \\
\hline & 2018 & 26.3 \\
\hline
\end{tabular}

teachers within each teaching area.

The reports present projects developed from pre-school education to grade 12 in secondary education, in the areas of Early Childhood Education, Primary Education, Portuguese, Spanish, English, Science, Mathematics, History, Geography, Philosophy, and Music (the area of Informatics was not included because the program was discontinued). Reports are the final product of the practicum experience and no revisions are made after the public defense. They present student teachers' inquiry-based teaching projects from a descriptive-interpretative stance, referring to the topic and objectives of inquiry, the context, relevant educational policies and theory, teaching approaches, data collection and analysis, and conclusions.

A grid for content analysis was built in 2012/13 on the basis of the model's expected outcomes (intended quality), including predefined items on three aspects of inquiry-based teaching: transformative vision of education (conceptions of pedagogy, the teacher and the learner); construction of multifaceted professional knowledge (type and role in project development); and the articulation between research and teaching (objectives; approach to inquiry; data collection methods). These aspects are not categories since they are not mutually exclusive (e.g., report excerpts documenting student teachers' visions of education may also contain elements of their professional knowledge). In section 5, the tables referring to report analysis integrate the grid items.

The analysis required the extensive, iterative reading of the reports in order to annotate the presence or absence of the grid items. Presence was understood as an indicator of quality since the items derive from the model's expected outcomes. It was inferred not only from the student teachers' assertions (what they said), but also from their approach to teaching and inquiry (what they did). For example, a conception of the learner as a reflective and active participant in learning may be inferred from the use of learnercentered teaching strategies or the analysis of learner feedback to evaluate and improve teaching. Since the degree of explicitness of the grid items varied among reports, a broad distinction was made between 'evident/clear presence' (indicated as ' $\sqrt{ }$ ') and 'not very evident/unclear presence' (indicated as '?'), which allowed us to identify areas for further improvement. Qualitative notes were taken on problems identified by the researchers regarding the conduction of inquiry, and also on the student teachers' accounts of project impact on themselves and their students.

To increase inter-rater reliability in the use of the grid, it was initially validated through a collaborative analysis of one report, which led to revisions and intersubjective agreement on how grid items applied to reports. Each report was subsequently analyzed by two team members so as to allow for the confrontation of results and decrease subjectivity as much as possible. These procedures increased the interpretative validity of the results through enhancing the accuracy of the interpretations made (Martella et al., 1999).

\section{Findings}

The findings presented and discussed below refer to the potential and shortcomings of inquiry-based professional learning within the practicum model. In line with the two research questions formulated above, they were organized into two topics: Developing competences for inquiry-based teaching; Developing professional knowledge and a transformative vision of education. 


\subsection{Developing competences for inquiry-based teaching}

Loughran (2009, p. 200) argued that "If teaching is to be understood as something more than an array of actions or trained approaches to 'doing', then there must be a mechanism for teachers to recognize, articulate, and build upon their knowledge of practice in real and meaningful ways". Inquiry can be that mechanism, which in our case entailed putting in place a number of strategies to support it (see Fig. 1 above): lesson observation and context analysis, theoretical readings, ongoing reflection on and research into practice, exploration of learner-centered approaches, portfolio and report writing, supervisory conferences, and university-based seminars. These strategies were listed in one of the survey questions and participants were asked to rate their importance for the student teachers' professional development according to their experience as supervisors/cooperating teachers and trainees, using the following scale: No Opinion, Not Important, Little Important, Moderately Important, Important, Very Important.

Table 3 presents the distribution of the most frequent responses - 'important' and 'very important' - and the mode and median values. The supervisors' and cooperating teachers' results were grouped because the response distribution was similar and the mode and median values were the same. Results showed that the participants' perceptions were globally aligned with the model's rationale, although the supervisors and cooperating teachers assessed the strategies more positively than the student teachers. The latter were particularly hesitant regarding the importance of university-based seminars and portfolios, which were the only items marked as 'moderately important' in above $20.0 \%$ of the responses ( $22.6 \%$ and $24.0 \%$ respectively), and also as 'not important' or 'little important' in $6.0 \%-9.0 \%$ of the responses. In their justifications, student teachers refer mostly to an intensified workload and the fact that some seminars are detached from their practical concerns.

Reports are expected to demonstrate the student teachers' competences (knowledge, capacities and attitudes) for undertaking inquiry-based teaching. The survey collected the supervisors' and former student teachers' perceptions on the extent to which those competences were evident in the reports that were supervised (supervisors) or produced (former student teachers), using the following scale: No Opinion, Not Evident, Little Evident, Moderately Evident, Evident, Very Evident. Cooperating teachers did not answer this question because they are not responsible for overseeing the reports.

Table 4 presents the mode and median values and the distribution of the most frequent responses - 'moderately evident', 'evident' and 'very evident' in the case of supervisors, and 'evident' and 'very evident' in the case of student teachers. Overall, the results reflected a positive view of the competences demonstrated in reports, although this time the supervisors' perceptions were less positive than the student teachers' and also more varied, with mode values ranging from 3 to 5 . This may be due to a greater awareness of student teachers' difficulties, and it is especially important to note their moderate rating of aspects related with the student teachers' research literacy, namely their knowledge about and ability to conduct inquiry.

Report analysis confirmed that student teachers' declarative or propositional research knowledge - knowledge about pedagogical research - is almost absent from their discourse, that is, they rarely refer to the literature on research methodology. This finding was already present in previous studies and led to the creation of a practicum seminar on pedagogical inquiry some years ago. More research training appears to be needed and supervisors should pay more attention to this aspect in supporting report writing. In this regard, the exploration of professional problems using researchbased methods and literature by the student teachers and the role of academic reading in integrating research- and practicebased knowledge have been advocated (Afdal \& Spernes, 2018; Bjørndal, 2020). It is important to note, however, that these students are new to pedagogical inquiry, many are also teaching for the first time (41.4\% in this study), and their project is small-scale and individual. Therefore, expectations regarding research declarative knowledge must keep realistic.

In contrast with the lack of declarative research knowledge, procedural or practical knowledge on how to conduct classroombased inquiry is well documented in all the reports despite the supervisors' hesitations in their responses to the survey, namely in the use of multiple data collection strategies in the phases of project design and implementation. Given the importance of both phases of project development, Table 5 presents the frequency of strategies across the 44 reports in each phase. There was a total of 298 occurrences in both phases, with a balanced distribution between them (45\% and 55\%). However, triangulation procedures were clearly evident in only about half of the reports, that is, a lot of student teachers revealed difficulties in comparing data collected with different methods or at different points in time, thus providing a fragmented rather than a holistic view of their findings.

Inquiry strategies were used to collect two types of data (Zwozdiak-Myers, 2012): data to design and monitor intervention plans, mostly referring to indirect evidence of learning, that is, teachers' and learners' perceptions and opinions gathered through observations, reflective records, questionnaires or self-regulation

Table 3

Perceptions of the importance of strategies supporting inquiry.

\begin{tabular}{|c|c|c|c|c|c|c|c|c|}
\hline & \multicolumn{4}{|c|}{ Ss \& CTs $(n=146)$} & \multicolumn{4}{|c|}{ Former STs $(n=133)$} \\
\hline & I & VI & Mo & $\mathrm{Me}$ & I & VI & Mo & $\mathrm{Me}$ \\
\hline & $\%$ & $\%$ & $1-5$ & $1-5$ & $\%$ & $\%$ & $1-5$ & $1-5$ \\
\hline Lesson observation and contexts analysis & 13.7 & 84.2 & 5 & 5 & 31.6 & 43.6 & 5 & 4 \\
\hline Development of a pedagogical project & 19.2 & 74.0 & 5 & 5 & 26.3 & 50.4 & 5 & 5 \\
\hline Exploration of current teaching methodologies & 24.0 & 69.9 & 5 & 5 & 26.3 & 53.4 & 5 & 5 \\
\hline Teaching with a humanistic and democratic orientation & 24.7 & 68.5 & 5 & 5 & 25.6 & 48.1 & 5 & 4 \\
\hline Theoretical grounding of professional choices & 32.2 & 56.8 & 5 & 5 & 33.1 & 37.6 & 5 & 4 \\
\hline Ongoing reflection about practice & 6.8 & 89.0 & 5 & 5 & 29.3 & 52.6 & 5 & 5 \\
\hline Research into practice so as to understand and improve it & 20.5 & 73.3 & 5 & 5 & 29.3 & 53.4 & 5 & 5 \\
\hline Supervisory support at school & 20.5 & 73.3 & 5 & 5 & 22.6 & 51.1 & 5 & 5 \\
\hline Supervisory support at the university & 20.5 & 74,7 & 5 & 5 & 22.6 & 50.4 & 5 & 5 \\
\hline University-based seminars to support the practicum & 33.6 & 52.7 & 5 & 5 & 28.6 & 30.1 & 5 & 4 \\
\hline Reflective portfolio focused on the project & 43.8 & 39.7 & 4 & 4 & 34.6 & 26.3 & 4 & 4 \\
\hline Project report & 45.9 & 43.8 & 4 & 4 & 36.8 & 38.3 & 5 & 4 \\
\hline
\end{tabular}

Ss: Student Teachers; CTs: Cooperating Teachers; I: Important; VI: Very Important; Mo: Mode; Me: Median. 
Table 4

Perceptions of whether competences for inquiry-based teaching are evident in reports.

\begin{tabular}{|c|c|c|c|c|c|c|c|c|c|}
\hline & \multicolumn{5}{|c|}{ Ss $(n=34)$} & \multicolumn{4}{|c|}{ Former STs $(\mathrm{n}=133)$} \\
\hline & ME & $\mathrm{E}$ & VE & Mo & Me & $\mathrm{E}$ & VE & Mo & Me \\
\hline & $\%$ & $\%$ & $\%$ & $1-5$ & $1-5$ & $\%$ & $\%$ & $1-5$ & $1-5$ \\
\hline Knowledge of the practicum context & 5.9 & 35.3 & 58.8 & 5 & 4 & 40.6 & 48.9 & 5 & 4 \\
\hline Knowledge of education and didactics & 17.6 & 61.8 & 17.6 & 4 & 4 & 48.9 & 39.1 & 4 & 4 \\
\hline Adoption of current didactic perspectives & 11.8 & 58.8 & 23.5 & 4 & 4 & 33.1 & 54.1 & 5 & 5 \\
\hline Knowledge of content in teaching field & 14.7 & 52.9 & 32.4 & 4 & 4 & 41.4 & 45.1 & 5 & 4 \\
\hline Knowledge about pedagogical research & 35.3 & 44.1 & 5.9 & 4 & 4 & 42.1 & 42.9 & 5 & 4 \\
\hline Ability to justify choices & 35.3 & 52.9 & 11.8 & 4 & 4 & 37.6 & 51.1 & 5 & 5 \\
\hline Ability to describe practice & 20.6 & 52.9 & 26.5 & 4 & 4 & 33.1 & 56.4 & 5 & 5 \\
\hline Ability to articulate practice with theory & 35.3 & 55.9 & 5.9 & 4 & 4 & 37.6 & 48.1 & 5 & 4 \\
\hline Ability to investigate practice & 44.1 & 44.1 & 8.8 & 3 & 4 & 45.1 & 42.1 & 4 & 4 \\
\hline Ability to identify project potentialities & 38.2 & 47.1 & 11.8 & 4 & 4 & 38.3 & 48.9 & 5 & 4 \\
\hline Ability to identify project limitations & 41.2 & 41.2 & 14.7 & 3 & 4 & 36.1 & 52.6 & 5 & 5 \\
\hline Ability to propose future actions & 55.9 & 32.4 & 8.8 & 3 & 4 & 40.6 & 45.9 & 5 & 4 \\
\hline Attitude of openness to change & 23.5 & 47.1 & 26.5 & 4 & 4 & 27.8 & 57.9 & 5 & 5 \\
\hline Commitment towards the profession & 20.6 & 50.0 & 26.5 & 4 & 4 & 29.3 & 57.9 & 5 & 5 \\
\hline Building a personal vision of education & 47.1 & 38.2 & 5.9 & 3 & 4 & 37.6 & 46.6 & 5 & 4 \\
\hline
\end{tabular}

Ss: Supervisors; CTs: Cooperating Teachers; STs: Student Teachers; ME: Moderately Evident; E: Evident; VE: Very Evident; Mo: Mode; Me: Median.

Table 5

Frequency of data collection strategies in the project reports $(n=44)$.

\begin{tabular}{|c|c|c|c|c|}
\hline & \multirow{2}{*}{$\frac{\text { Project Design }}{\mathrm{f}}$} & \multirow{2}{*}{$\frac{\text { Project Implementation }}{\mathrm{f}}$} & \multicolumn{2}{|c|}{ Total } \\
\hline & & & $\mathrm{f}$ & $\%$ \\
\hline Non-structured observation (field notes) & 35 & 27 & 62 & 20.8 \\
\hline Questionnaires & 19 & 26 & 45 & 15.1 \\
\hline Teacher reflective records (portfolio) & 15 & 24 & 39 & 13.1 \\
\hline Document analysis & 30 & 4 & 34 & 11.4 \\
\hline Analysis of learning tasks (artifacts) & 4 & 23 & 27 & 9.0 \\
\hline Analysis of classroom interaction & 11 & 14 & 25 & 8.4 \\
\hline Learner self-regulation tools & 1 & 20 & 21 & 7.0 \\
\hline Structured observation (grid, guidelines ...) & 14 & 5 & 19 & 6.4 \\
\hline Knowledge assessment of (e.g. tests) & 5 & 11 & 16 & 5.4 \\
\hline Learner reflective records (e.g. journal) & 0 & 8 & 8 & 2.7 \\
\hline Interviews & 0 & 2 & 2 & 0.7 \\
\hline Total $(f)$ & 134 & 164 & 298 & \\
\hline Total (\%) & 45 & 55 & 100 & \\
\hline
\end{tabular}

tools; and data to evaluate the effectiveness of interventions on learning performance, referring to more direct evidence of learning mostly collected through the analysis of classroom interaction or student work, and tests. Table 5 shows a predominance of strategies focused on teachers' and learners' perceptions of and opinions on pedagogical processes, which is central to the development of an inquisitive stance towards teaching (Clarke \& Erickson, 2003b). Nevertheless, a greater focus on projects' impact on learning outcomes might be achieved through fostering formative assessments of subject learning and using protocols for analyzing student artifacts (Burnaford, 2001).

Regarding modes of inquiry, even though action research is recommended, reports account for three rather different approaches (Table 6 ) and only 22 reports $(50.0 \%)$ document cycles of planning-acting-observing-reflecting, allowing readers to understand connections between data collection, decision-making, and pedagogical action. Those connections are less evident in the other reports, where data collection during the intervention may or may not occur, and a final evaluation and/or the use of pre-/post-tests are preferred.

Two orientations to inquiry seem to emerge: action research favors inquiry as a context-sensitive, flexible, creative decisionmaking process where student teachers plan and readjust teaching based on ongoing data collection and reflection, whereas the other approaches are mostly related to the implementation and evaluation of specific methods or techniques (e.g., problem-based learning, conceptual change approach, etc.) (Zeichner \& Conklin, 2008). Variations in modes of inquiry may be related to different research traditions across disciplinary fields and to teacher educators' personal research experiences and preferences (Brew \& Saunders, 2020), but further research is needed to confirm this hypothesis.

Student teachers' reports rarely account for a notion of inquiry that incorporates teachers' critique of evidence from existing

Table 6

Approaches to inquiry in reports $(n=44)$.

\begin{tabular}{lll}
\hline & f & \\
\hline Action research (cycles de planning-acting-observing-reflecting) & 50.0 \\
(Diagnosis) $\rightarrow$ Intervention with data collection $\rightarrow$ Evaluation of impact & 22 & 15 \\
Pre-test $\rightarrow$ Intervention with no data collection $\rightarrow$ Post-test + Evaluation of impact & 34.1 & 7.0 \\
\hline
\end{tabular}




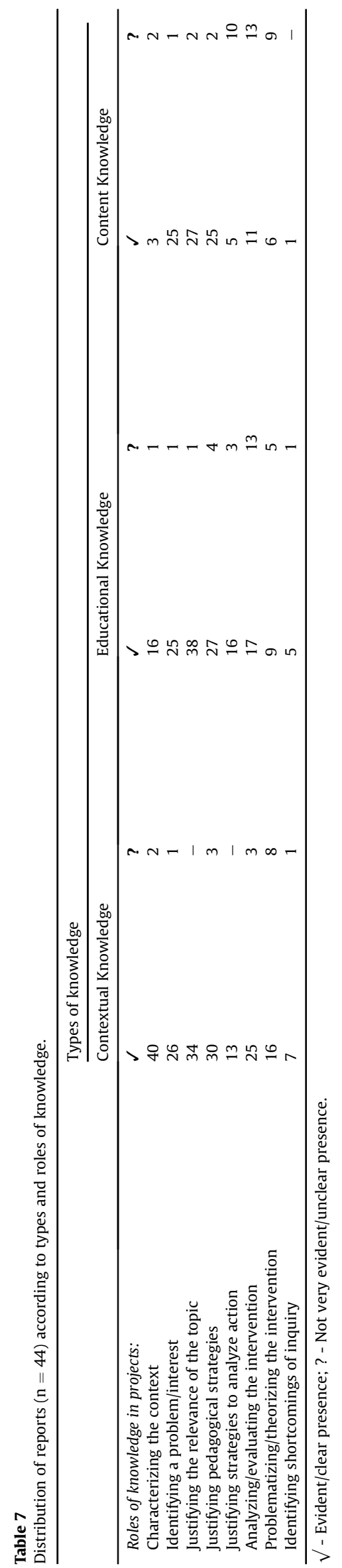

research and the adaptation of research findings to design effective teaching strategies (Evans et al., 2017, p. 404). Instead, they account for inquiry as a reflective learning-to-teach experience that is not necessarily dependent upon previous research findings (Burnaford, 2001; Smith, 2018). Student teachers analyze data to interpret, evaluate and reshape teaching on the basis of their contextual knowledge and their views of 'good' educational practice. The most important criterion for assessing the quality of inquiry in this context is a personal one: "Did this make a difference to my classroom?" (Mitchell, 2003, p. 206). Interpretations and conclusions are primarily for the 'here and now' and relate directly to teacher and learner growth, even though professional learning may extend beyond immediate practice and be useful for other teachers (Burnaford, 2001). This form of inquiry can limit the development of student teachers' research literacy, but it appears to be appropriate to candidate teachers who are just beginning to learn how to do it. Research-informed teaching, whereby teachers transfer research knowledge into practice with the support of expert researchers, is perhaps too ambitious in ITE settings, which highlights the contextual nature of rationality in ITE programs (Brew \& Saunders, 2020).

\subsection{Developing professional knowledge and a transformative vision of education}

Seeing the practicum as a hybrid 'third space' where theory, research and experience meet and diverse rationales can be negotiated (Zeichner, 2010) requires moving away from a longstanding tradition in educational theory and practice that has reinforced the superiority of expert knowledge over teachers' practical knowledge (Bell, 2001, p. 42). Inquiry-based teaching promotes the development of multifaceted professional knowledge emerging from systematic reflection on practice. This was confirmed by the participants' perceptions regarding evidence of student teachers' knowledge in reports - knowledge about the practicum context, education and didactics, current didactic perspectives, content in teaching field and pedagogical research (median value $=4$ for all items in Table 4 above). It was further confirmed by report analysis, which showed that student teachers mobilized three main types of knowledge - contextual, educational and content knowledge - with diverse roles in project development. Table 7 indicates the number of reports where these types of knowledge were used (more or less evidently) in association with their roles in project development tasks.

Context knowledge, referring to variables that affect pedagogy directly or indirectly (educational policies, curricula, course books, school environments and regulations, learners' needs and interests, mainstream classroom practices...), appears to play a central role and its marked presence in reports was also confirmed in the survey by both the supervisors and the former student teachers (see Table 4: mode $=5$; median $=4$ ). This type of knowledge is not just related to the stage of project design, where context analysis is crucial; it permeates the whole process of inquiry and it can be seen in student teachers' reflections on why they did what they did, what went well or wrong and why, and what was done to surpass problems.

Educational and content knowledge are also connected to all the stages of inquiry. The latter is patent in student teachers' understandings of the discipline they teach and want their students to learn, influencing their decisions regarding what was important to teach/learn and why, what their students learnt and how they progressed, what difficulties they had and why. As for educational knowledge, which includes didactic knowledge, it appears to be mostly "appropriated in the cause of educational change" (Carr, 2006, p. 155). Rather than seeing theory as the truth 
Table 8

Conceptions of pedagogy, the teacher and the learner in reports $(n=44)$.

\begin{tabular}{|c|c|c|c|}
\hline Student teachers' conceptions of ... & & $\checkmark$ & $?$ \\
\hline Pedagogy & Democratic, inclusive, learning-centered & 27 & 8 \\
\hline The teacher & Reflective, agent of change & 30 & 8 \\
\hline The learner & Reflective, constructor of knowledge & 27 & 12 \\
\hline
\end{tabular}

$\sqrt{ }$ - Evident/clear presence; ? - Not very evident/unclear presence.

and practice as given, the problematic nature of both is enacted through "the moral disposition [...] to act rightly, truly, prudently and responsively to circumstances" (Carr \& Kemmis, 1986, p. 42). Theoretical knowledge is primarily used by student teachers to support their pedagogical beliefs and justify their choices, not to fill in some research gap in the literature and contribute to wider theoretical knowledge (Burnaford, 2001; Loughran, 2003; Smith, 2018).

The use of educational knowledge for analyzing and theorizing pedagogical interventions is not clearly evident in a lot of reports (see Table 7), which can be partially explained by the student teachers' inexperience, but also by a prevailing theoretical approach across the curriculum. A previous study of the MA curricula (Vieira et al., 2019), involving the qualitative analysis of the syllabi of 55 different course units distributed across all training components, revealed that only 21 syllabi (38.2\%) make an explicit reference to practice-related tasks, which may include the analysis of educational documents, the analysis of school contexts, the analysis of teaching practices and resources, and teaching practice itself. These types of tasks are present in the practicum, moderately present in the course units of didactics, much less present in the general education course units, and mostly absent from the course units in the teaching subject area. This means that curricula may not provide enough opportunities for students to understand the significance of their theoretical learning for teaching practice, which surely affects their ability to theorize it in the practicum.

In developing a self-determined, dynamic form of theoretical understanding that is intrinsically connected with their ongoing efforts to make sense of practice in line with their values and hopes (McNiff, 2013), student teachers are expected to build a personal vision of education, which is one of the main dimensions of teacher professionalism (Fullan, 1995). However, survey results revealed supervisors' hesitations regarding report evidence on the student teachers' ability to build that vision (see Table 4 : mode $=3 /$ median: 4). In report analysis, we tried to understand whether student teachers positioned themselves in favor of a humanistic and democratic rationale by looking at their conceptions of pedagogy, teachers and learners, inferred from the pedagogical assumptions they subscribed to or advocated, the strategies they explored, and their reflections on practice. Table 8 shows that those conceptions were globally aligned with a transformative vision of education, even though not on all cases and not always in an explicit way.

The construction of transformative understandings of teaching and learning is evident as student teachers question established practices and seek to reshape them in line with their pedagogical ideals and classroom data. A learner-centered orientation is present in their pedagogical assumptions and teaching strategies, and also in the interpretation of learner data to assess the impact of teaching and make it more adjusted to learner needs and interests, which contributes to their own development as responsive educators. Moreover, their action plans often extend teaching goals beyond disciplinary competences so as to develop learners' lifelong learning competences, like cooperative learning, intercultural competence, citizenship skills, critical thinking, and self-directed learning.

In their report conclusions, all student teachers evaluate their experience of inquiry positively and highlight learning benefits that are closely related with their focus of inquiry, recommending educational change based on their findings. However, most of them also realize that they would need more time to develop their projects further and achieve more solid outcomes. Apart from time constraints, is also important to note that the development of a transformative vision of education may find resistance in schools, and one of the potential problems affecting innovation through inquiry in practicum settings is the clash between traditional pedagogical cultures in schools and the progressive views promulgated in ITE programs (Sykes, Bird, \& Kennedy, 2010). Previous studies on the model, involving focus group interviews to faculty supervisors, revealed that this may constitute a critical aspect of their role and one of the reasons why supervisory support may fall short of intended outcomes regarding innovation (Flores et al., 2016).

Limitations to innovation also result from the fact that projects are required to be carried out individually, although they are supported by supervisors and cooperating teachers. A more collaborative approach to inquiry might offer student teachers opportunities to experience a reality of teaching that reflects extended professionalism (Willegems, Consuegra, Struyven, \& Engels, 2018). This would entail a substantial change in current practicum arrangements and assessment procedures, namely by allowing student teachers to develop and report collaborative projects undertaken with their peers, the cooperating teachers or other teachers. Although collaboration is encouraged, the fact that teacher qualifications are now obtained at master level means that student teachers' reports are expected to account for individual professional competences, and this limits the scope of collaborative work in project design and development.

\section{Conclusions and discussion}

\subsection{Inquiry-based practicum and its contribution to professional learning}

The study findings show that the practicum model promotes the development of inquiry competences, multifaceted professional knowledge and personal visions of education based on humanistic and democratic values, which may enhance student teachers' professional agency (van der Heijden et al., 2015). Shortcomings were also observed, mainly regarding declarative research knowledge and connections between educational theory and practice, calling for greater efforts to support student teachers in this regard (Afdal \& Spernes, 2018; Bjørndal, 2020; Burnaford, 2001).

Overall, the participants' perceptions (perceived quality) and report evidence (inferred quality) appear to be globally aligned with the model's intended processes and outcomes (intended quality). This is a good indicator of the model's consistency, which is partly due to the fact that its rationale and strategies are explicitly stated in support documents and discussed with practicum participants in coordination meetings, supervisory conferences, and in the initial training course for cooperating teachers. Seeking a convergence of understandings and practices implies some degree of control over how inquiry is to be developed, but the model also 
allows a significant amount of decision-making freedom as regards the focus and implementation of inquiry, which are negotiated among student teachers, cooperating teachers and supervisors. Finding a balance between control and freedom is a central feature of ITE programs that value inquiry-based learning (Brew \& Saunders, 2020), and setting up a framework for inquiry can be empowering as long as it is validated by participants. Survey findings suggest that our participants valued the model's strategies, and reports account for the student teachers' satisfaction with their experience of inquiry.

Nevertheless, the findings also indicate that the models' intended outcomes are achieved at different levels. Survey results showed variations in how participants perceived the evidence of inquiry competences in reports, and report analysis showed variations of explicitness in student teachers' visions of education, use of action research, triangulation of data collected, and use of educational knowledge for analyzing and theorizing practice. Inquiry does not have to follow a unique formula, but enhancing the educational value of the model for all student teachers would increase its inclusiveness. Therefore, research into inquiry-based professional learning needs to look more closely at inquiry-inaction so as to understand what enhances and hampers it. A more ethnographic approach, namely through observational methods, would allow a deeper understanding of professional learning processes and how these might be fostered. In particular, it would be important to investigate the role of supervisors and cooperating teachers as facilitators of inquiry. Research has pointed to existing tensions and challenges related to mentoring and mentor feedback in the practicum (Beek, Zuiker, \& Zwart, 2019; Bjørndal, 2020; Clarke \& Mena, 2020), to ethical dilemmas during practicum (Lilach, 2020), and to the importance of content-focused coaching in professional learning (Becker, Waldis, \& Staub, 2019). However, other issues may be raised, namely the extent to which the supervision of inquiry entails an emancipatory agenda and promotes student teachers' autonomy as decision-makers (Brew \& Saunders, 2020).

In ITE settings, action research can have different goals: reflective practice; participatory, critical inquiry; and teacher leadership to effect change in schools and communities (Vaughan \& Burnaford, 2016). Zeichner (2009, p. 69) argued that teacher inquiry should move beyond personal renewal and embrace broader political purposes regarding the social struggle for greater justice. In the present case, student teachers are encouraged to assume a critical stance and transform the conditions of teaching and learning, but their inquiry is individual, small-scale, and only focused on classroom processes, which clearly limits its scope and impact. Their reports do account for the main goal of teachers as researchers: "to understand their own particular practices as they emerge in their own particular circumstances, without reducing them to the ghostly status of the general, the abstract or the ideal or, perhaps one should say, the unreal" (Kemmis \& Wilkinson, 1998, p. 25). Nevertheless, a more transformative stance might be enhanced through greater negotiation with schools and a closer link between the practicum and other course units where students learn about progressive educational theories without necessarily understanding their relevance to practice. Inquiry-based learning needs to permeate ITE curricula more intentionally and systematically, rather than being left almost exclusively to the practicum.

The study illustrates the importance of self-studies for enhancing teacher educators' role as producers of knowledge and agents of change in ITE institutions (Loughran, 2007; Zeichner, 2007). Actually, improvements of the practicum model over the last decade were partially influenced by previous studies (see Vieira et al., 2019). However, there is a larger landscape that places inquiry-based professional learning in a space of tension. The feasibility, scope and impact of inquiry in practicum settings are not detached from historical and structural factors that make it both necessary and controversial. Constraints to its development can be found in academic research cultures, ITE programs and school cultures. We now turn to that landscape, where unresolved issues call for changes at those levels.

\subsection{Constraints to inquiry and future directions}

What Zeichner (2009) stated a decade ago still rings true in many academic settings: "The guardians of the knowledge base in education have become more willing to tolerate action research, but when it comes to defining what real educational research is, action research does not seem to count" (p. 79). If we accept that the purposes, motives and audience of teacher inquiry are different from those of traditional academic research (Burnaford, 2001; Smith, 2018), then we need to move away from academic orthodoxies and be prepared to value educational relevance over methodological rigor, which implies accepting eclectic methodologies that put pedagogical significance first.

This position is surely controversial, although from a critical constructivist angle it might actually be extended to educational research in general, since the complexity and ambiguousness of educational issues requires the abandonment of a positivistic sense of rigor in favor of the search for significance (Kincheloe, 2003, p. 163). Schön's (1987) topographic metaphor of the 'swampy lowland' of practice where "messy, confusing problems defy technical solution" (p. 3) raises a central dilemma for teachers and teacher educators: "The practitioner must choose. Shall he remain on the high ground where he can solve relatively unimportant problems according to prevailing standards of rigor, or shall he descend to the swamp of important problems and nonrigorous inquiry?" (sic) (Schön, 1987, p. 3). When 'important problems' matter, then some balance between rigor and relevance needs to be achieved. Rather than engaging in disputes over what counts as research, we need to ask how inquiry can be put at the service of pedagogy. The answer to that question is always dependent on who does research, for whom, why and for what. Research done by teachers and for teachers and their learners does not have to comply with academic norms and requires methodologies that are context-sensitive and primarily oriented towards teacher and learner development and the improvement of educational practice (Smith, 2018, p. 31).

Another factor worth considering within academic cultures is the status and role of teacher educators as an increasingly diverse, occupational group due to the marketization of teacher education (White, 2019). Recent studies have pointed out tensions in their role as teachers and researchers (Smith \& Flores, 2019), as well the need to investigate relations between work pressure and opportunities for professional growth, work related basic needs satisfaction, and their researcherly disposition (Tack \& Vanderlinde, 2019). In a study of European policy documents about teacher education, Snoek, Swennen, and van der Klink (2010, p. 45) stressed the limited attention given to teacher educators and their professional development, recommending the construction of conceptual frameworks for the induction and further development of teacher educators as a specialized professional group whose work largely determines the innovative potential of ITE programs and the quality of teaching.

As regards ITE curricula, they can prepare prospective teachers for inquiry through pedagogies that include classroom interventions, microteaching and simulations, cases, portfolios, and journals (Grossman, 2005). Nevertheless, a theory-to-practice rationale still prevails in many ITE programs where the practicum is located at the end of the training process and conceived as a curricular space devoted to applying theoretical knowledge to 
teaching. Enhancing connections to the world of practice across ITE curricula would enhance students' ability to explore relations between theory and practice, and to appreciate and deal with the complexities of educational experience. This would make curricula more student-centered, supporting the development of an inquisitive stance towards the profession. As Symeonidis (2018, p. 24) pointed out, although the Bologna reform had a significant impact on the structure of teacher education systems, the shift towards more student-centered methodologies remains ambiguous and requires more time.

Constraints to inquiry-based professional learning can also be found in school cultures. Policy recommendations issued by the European Commission have emphasized the role of teacher inquiry for sustained innovation, as well as the need to foster partnerships between schools, universities and other organizations to enhance research-informed teaching (European Commission, 2015, p. 5). However, inquiry is not part of everyday life in most schools. As Mitchell (2003) asserted, its development poses a number of challenges to teachers, like the fear of leaving their comfort zone, costs of time and energy, difficulties in dealing with the research literature and in making their work public, lack of external rewards, and parental suspicion towards experimentation. Moreover, pressures to cover national curricula and prepare students for external exams also hinder opportunities for inquiry and innovation.

Given these circumstances, to what extent can ITE programs be expected to make a difference in schools? ITE institutions often adopt a critical attitude towards school cultures and hold unrealistic expectations regarding the impact of their programs on changing those cultures, hoping to transform them against the weight of dominant traditions and circumstances (Sykes et al., 2010, p. 468). ITE programs can make a difference, but we also need to accept that "No matter what we do in our practitioner education programs, and no matter how well we do them, at best we can only prepare practitioners to begin practice" (Zeichner, 2009, p. 73). Moreover, the impact of inquiry upon student teachers' professional identity within ITE programs is not a predictor of how they will feel, think and act as teachers beyond ITE.

The role of ITE on changing the profession will largely depend on how teacher education policies and cultures of teaching evolve so as to enable innovation based on teacher inquiry (European Commission, 2015). This requires the existence of induction and in-service programs based on 'action inquiry' that is responsive to the practitioners' learning orientations and the needs of schools (Bell, 2001), along with the reinforcement of partnerships and collaborative inquiry between teacher education institutions and schools (BERA-RSA, 2014; Kemmis \& Wilkinson, 1998; Willegems et al., 2018). Inquiry-based models in ITE programs can push these conditions forward by preparing teachers with an inquisitive mind and a determination to enact change. Investigating those models is crucial to understand and enhance their formative value, to reshape teacher professionalism, and to envisage new scenarios for life in schools.

\section{Acknowledgements}

The research team wishes to thank the supervisors, cooperating teachers and former student teachers who collaborated in the study, and also to the colleagues who participated in report analysis in previous studies. This research did not receive any specific grant from funding agencies in the public, commercial, or not-for-profit sectors. It was supported through national funds of FCT/MCTESPT at the University of Minho, by CIEd (Research Centre on Education, projects UIDB/01661/2020 and UIDP/01661/2020 - Institute of Education), CIEC (Research Centre for Child Studies, project UIDB/00317/2020 - Institute of Education), and CBMA (Centre of
Molecular and Environmental Biology, project UIDB/04050/2020 School of Sciences).

\section{References}

Afdal, H. W., \& Spernes, K. (2018). Designing and redesigning research-based teacher education. Teaching and Teacher Education, 74, 215-228. https:// doi.org/10.1016/j.tate.2018.05.011

Atweh, B., Kemmis, S., \& Weeks, P. (Eds.). (1998). Action research in practice. Partnerships for social justice in education. London: Routledge.

Bassey, M. (1999). Case study research in educational settings. Buckingham: Open University Press.

Becker, E. S., Waldis, M., \& Staub, F. C. (2019). Advancing student teachers' learning in the teaching practicum through content-focused coaching: A field experiment. Teaching and Teacher Education, 83, 12-26. https://doi.org/10.1016/ j.tate.2019.03.007

Beek, G. J., Zuiker, I., \& Zwart, R. C. (2019). Exploring mentors' roles and feedback strategies to analyze the quality of mentoring dialogues. Teaching and Teacher Education, 78, 15-27. https://doi.org/10.1016/j.tate.2018.10.006

Bell, G. H. (2001). Action inquiry. In G. Burnaford, J. Fischer, \& D. Hobson (Eds.), Teachers doing research (pp. 40-53). New York: Routledge.

Bera-Rsa. (2014). Research and the teaching profession: Building the capacity for a selfimproving education system. Final report of the BERA (British Educational Research Association) and RSA. London: The Royal Society for Arts, Manufactures and Commerce) inquiry into the role of research in teacher education. Retrieved from https://www.thersa.org/discover/publications-and-articles/reports/ research-and-the-teaching-profession-building-the-capacity-for-a-selfimproving-education-system.

Bjørndal, C. R. P. (2020). Student teachers' responses to critical mentor feedback: A study of face-saving strategies in teaching placements. Teaching and Teacher Education, 91. https://doi.org/10.1016/j.tate.2020.103047

Brew, A., \& Saunders, C. (2020). Making sense of research-based learning in teacher education. Teaching and Teacher Education, 87. https://doi.org/10.1016/ j.tate.2019.102935

Bullock, S. M. (2016). Teacher candidates as researchers. In J. Loughran, \& M. L. Hamilton (Eds.), International handbook of teacher education (pp. 379-403). Dordrecht: Springer Press.

Burnaford, G. (2001). Teachers' work: Methods for researching teaching. In G. Burnaford, J. Fischer, \& D. Hobson (Eds.), Teachers doing research (pp. 36-60). New York: Routledge. https://doi.org/10.4324/9781410605641.

Burnaford, G., Fischer, J., \& Hobson, D. (Eds.). (2001). Teachers doing research. New York: Routledge. https://doi.org/10.4324/9781410605641.

Cain, T. (2015). Teachers' engagement with published research: Addressing the knowledge problem. Curriculum Journal, 26(3), 488-509. https://doi.org/ $10.1080 / 09585176.2015 .1020820$

Campos, B. (2010). Bologna and initial teacher education in Portugal. In B. Hudson, P. Zgaga, \& B. Åstrand (Eds.), Advancing quality cultures for teacher education in Europe: Tensions and opportunities (pp. 13-31). Umeå, Sweden: Umeå School of Education, Umeå University.

Canário, R. (2002). A prática profissional na formação de professores [Professional practice in teacher education]. In B. P. Campos (Ed.), Formação profissional de professores no ensino superior (pp. 31-45). Porto: Porto Editora.

Cao, Y., Postareff, L., Lindblom-Ylanne, S., \& Toom, A. (2019). Teacher educators' approaches to teaching and connections with their perceptions of the closeness of their research and teaching. Teaching and Teacher Education, 85, 125-136. https://doi.org/10.1016/j.tate.2019.06.013

Carr, W. (2006). Education without theory. British Journal of Educational Studies, 54(2), 136-159. https://doi.org/10.1111/j.1467-8527.2006.00344.x

Carr, W., \& Kemmis, S. (1986). Becoming critical. Education, knowledge and action research. Deakin: Deakin University Press.

Clarke, A., \& Erickson, G. (Eds.). (2003a). Teacher inquiry. London: Routledge. https:// doi.org/10.4324/9780203417669.

Clarke, A., \& Erickson, G. (2003b). Teacher inquiry. A defining feature of professional practice. In A. Clarke, \& G. Erickson (Eds.), Teacher inquiry (pp. 1-6). London: Routledge. https://doi.org/10.4324/9780203417669.

Clarke, A., \& Mena, J. (2020). An international comparative study of practicum mentors: Learning about ourselves by learning about others. Teaching and Teacher Education, 90. https://doi.org/10.1016/j.tate.2020.103026

Council of the European Union. (2007). Conclusions of the council and of the representatives of the governments of the member states meeting within the council of 15 november 2007, on improving the quality of teacher education. Official Journal of the European Union, 12 December 2007, C 300/6-9. Retrieved from https://op.europa.eu/en/publication-detail/-/publication/6027862c-6e904d92-a355-ff7322cd8044/language-en.

Ellis, V., Souto-Manning, M., \& Turvey, K. (2019). Innovation in teacher education: Towards a critical re-examination. Journal of Education for Teaching, 45(1), 2-14. https://doi.org/10.1080/02607476.2019.1550602

Estrela, M. A., Esteves, M., \& Rodrigues, A. (2002). Síntese da investigação sobre formação inicial de professores em Portugal (1990-2000) [Synthesis of research on initial teacher education in Portugal (1990-2000)]. Porto: Porto Editora.

European Commission. (2015). Schools policy Education \& Training 2020. Shaping career-long perspectives on teaching. A guide on policies to improve Initial Teacher Education. Retrieved from https://www.schooleducationgateway.eu/ 
downloads/files/Shaping\%20career-long\%20perspectives\%20on\%20teaching. pdf.

Evans, C., Waring, M., \& Christodoulou, A. (2017). Building teachers' research literacy: Integrating practice and research. Research Papers in Education, 32(4), 403-423. https://doi.org/10.1080/02671522.2017.1322357

Flores, M. A. (2018). Linking teaching and research in initial teacher education: Knowledge mobilisation and research-informed practice. Journal of Education for Teaching, 44(5), 621-636. https://doi.org/10.1080/02607476.2018.1516351

Flores, M. A., Vieira, F., Silva, J. L., \& Almeida, J. (2016). Integrating research into the practicum: Inquiring into inquiry-based professional development in postBologna initial teacher education in Portugal. In M. A. Flores, \& T. Al-Barwani (Eds.), Redefining teacher education for the post-2015 era: Global challenges and best practice (pp. 109-124). New York: Nova Publisher.

Formosinho, J. A. (2009). Academização da formação de professores [Academization of teacher training]. In J. Formosinho, \& Coord (Eds.), Formação de professores: Aprendizagem profissional e acção docente (pp. 73-92). Porto: Porto Editora.

Fuch, P., Fuch, G. E., \& Ness, L. R. (2018). Denzin's paradigm shift: Revisiting triangulation in qualitative research. Journal of Social Change, 10(1), 19-32. https:// doi.org/10.5590/JOSC.2018.10.1.02

Fullan, M. (1995). The limits and the potential of professional development. In T. R. Guskey, \& M. Hubeman (Eds.), Professional development in education. New paradigms and practices. New York: Teachers College Press, 353-267.

Grossman, P. (2005). Research on pedagogical approaches in teacher education. In M. Cochran-Smith, \& K. Zeichner (Eds.), Studying teacher education (pp. 425-476). New York: Routledge. https://doi.org/10.4324/9780203864043.

van der Heijden, H. R. M. A., Geldens, J. J. M., Beijaard, D., \& Popeijus, H. L. (2015). Characteristics of teachers as change agents. Teachers and Teaching, 21(6), 681-699. https://doi.org/10.1080/13540602.2015.1044328

van Katwijk, L., Berry, A., Jansen, E., \& van Veen, K. (2020). "It's important, but I'm not going to keep doing it!": Perceived purposes, learning outcomes, and value of pre-service teacher research among educators and pre-service teachers. Teaching and Teacher Education, 86. https://doi.org/10.1016/j.tate.2019.06.022

Kemmis, S., \& Wilkinson, M. (1998). Participatory action research and the study of practice, In B. Atweh, S. Kemmis, \& P. Weeks (Eds.), Action research in practice. Partnerships for social justice in education (pp. 21-26). London: Routledge.

Kincheloe, J. L. (2003). Teachers as researchers: Qualitative inquiry as a path to empowerment. London \& New York: Routledge Falmer.

Lilach, M. (2020). [Not] speaking truth to power: Ethical dilemmas of teacher candidates during practicum. Teaching and Teacher Education, 89. https:// doi.org/10.1016/j.tate.2019.103002

Loughran, J. (2003). Exploring the nature of teacher research. In A. Clarke, \& G. Erickson (Eds.), Teacher inquiry (pp. 181-189). London: Routledge. https:// doi.org/10.4324/9780203417669.

Loughran, J. (2007). Researching teacher education practices: Responding to the challenges, demands, and expectations of self-study. Journal of Teacher Education, 58(1), 12-20. https://doi.org/10.1177/0022487106296217

Loughran, J. (2009). Is teaching a discipline? Implications for teaching and teacher education. Teachers and Teaching, 15(2), 189-203. https://doi.org/10.1080/ 13540600902875290

Loughran, J., \& Menter, I. (2019). The essence of being a teacher educator and why it matters. Asia-Pacific Journal of Teacher Education, 47(3), 216-229. https:/l doi.org/10.1080/1359866X.2019.1575946

Lunenberg, M., \& Korthagen, F. (2009). Experience, theory, and practical wisdom in teaching and teacher education. Teachers and Teaching, 15(2), 225-240. https:// doi.org/10.1080/13540600902875316

Martella, R. C., Nelson, R., \& Marchand-Martella, N. E. (1999). Research methods. Learning to become a critical research consumer. Needham Heights, MA: Allyn \& Bacon.

Martin, A. K., \& Russell, T. (2009). Seeing teaching as a discipline in the context of pre-service teacher education: Insights, confounding issues, and fundamental questions. Teachers and Teaching, 15(2), 319-331. https://doi.org/10.1080/ 13540600902875381

Matheson, K., \& Edwards, C. M. (2016). Perspectives on knowledge mobilisation: An introduction to the Special Issue. Technology Innovation Management Review, 6(9), 4-8. Retrieved from https://timreview.ca/article/1014.

McNiff, J. (2013). Action research. Principles and practices (3rd ed.). Oxon \& New York: Routledge.

Mitchell, I. (2003). Why do teacher research? Perspectives from four stakeholders. In A. Clarke, \& G. Erickson (Eds.), Teacher inquiry (pp. 199-208). London: Routledge. https://doi.org/10.4324/9780203417669.

Moreira, M. A., \& Vieira, F. (2012). Pre-service teacher education in Portugal - The transformative power of local reform. In J. M. Paraskeva, \& J. Torres Santomé (Eds.), Globalisms and power - Iberian education and curriculum policies ( $\mathrm{pp}$. 94-105). New York: Peter Lang.

Puustinen, M., Santti, J., Koski, A., \& Tammi, T. (2018). Teaching: A practical or research-based profession? Teacher candidates' approaches to research-based teacher education. Teaching and Teacher Education, 74, 170-179. https:// doi.org/10.1016/j.tate.2018.05.004

Schön, D. (1987). Educating the reflective practitioner. San Francisco: Jossey-Bass Publishers.

Smith, K., \& Flores, M. A. (2019). The Janus faced teacher educator. European Journal of Teacher Education, 42(4), 433-446. https://doi.org/10.1080 02619768.2019.1646242

Smith, R. (2018). Research by teachers for teachers. In D. Xerri, \& C. Pioquinto (Eds.), Becoming research literate. Supporting teacher research in English language teaching (pp. 30-34). Sursee, Switzerland: English Teachers Association Retrieved from https://www.e-tas.ch/Becomingresearchliterate.

Snoek, M., Swennen, A., \& van der Klink, M. (2010). The teacher educator: A neglected factor in the contemporary debate on teacher education. In B. Hudson, P. Zgaga, \& B. Åstrand (Eds.), Advancing quality cultures for teacher education in Europe: Tensions and opportunities (pp. 33-48). Umeå, Sweden: Umeå School of Education, Umeå University.

Sykes, G., Bird, T., \& Kennedy, M. (2010). Teacher education: Its problems and some prospects. Journal of Teacher Education, 61(5), 464-476. https://doi.org/10.1177/ 0022487110375804

Symeonidis, V. (2018). Revisiting the European Teacher Education Area: The transformation of teacher education policies and practices in Europe. CEPS Journal, 8(3), 13-34. https://doi.org/10.26529/cepsj.509

Tack, H., \& Vanderlinde, R. (2019). Capturing the relations between teacher educators' opportunities for professional growth, work pressure, work related basic needs satisfaction, and teacher educators' researcherly disposition. European Journal of Teacher Education, 42(4), 459-477. https://doi.org/10.1080/ 02619768.2019.1628212

Tatto, M. T. (2020). What do we mean when we speak of research evidence in education? In L. Beckett (Ed.), Research-informed teacher learning (pp. 139-154). London: Routledge. https://doi.org/10.4324/9780429025822.

Vaughan, M., \& Burnaford, G. (2016). Action research in graduate teacher education: A review of the literature 2000-2015. Educational Action Research, 24(2), 280-299. https://doi.org/10.1080/09650792.2015.1062408

Vieira, F., Flores, M. A., Silva, J. L., \& Almeida, M. J. (2019). Understanding and enhancing change in post-Bologna pre-service teacher education: Lessons from experience and research in Portugal. In T. A. Barwani, M. A. Flores, \& D. Imig (Eds.), Leading change in teacher education. Lessons from countries and education leaders around the globe (pp. 41-57). Milton Park: Routledge.

Vieira, F., \& Moreira, M. A. (2008). Reflective teacher education towards learner autonomy: Moving towards a culture of possibility. In M. Jiménez Raya, \& T. Lamb (Eds.), Pedagogy for autonomy in language education - theory, practice and teacher education (pp. 266-282). Dublin: Authentik.

White, S. (2019). Once were teachers? Australian teacher education policy and shifting boundaries for teacher educators. European Journal of Teacher Education, 42(4), 447-458. https://doi.org/10.1080/02619768.2019.1628214

Willegems, V., Consuegra, E., Struyven, K., \& Engels, N. (2018). Pre-service teachers as members of a collaborative teacher research team: A steady track to extended professionalism? Teaching and Teacher Education, 76, 126-139. https://doi.org/10.1016/j.tate.2018.08.012

Zeichner, K. (2007). Accumulating knowledge across self-studies in teacher education. Journal of Teacher Education, 58(1), 36-46. https://doi.org/10.1177/ 0022487106296219

Zeichner, K. (2009). Teacher education and the struggle for social justice. New York: Routledge. https://doi.org/10.4324/9780203878767

Zeichner, K. (2010). Repensando as conexões entre a formação na universidade e as experiências de campo na formação de professores em faculdades e universidades [Rethinking connections between university-based training and field experiences at teacher education faculties and universities]. Educação, 35(3), 479-503. https://doi.org/10.5902/198464442357

Zeichner, K., \& Conklin, H. G. (2008). Teacher education programs as sites for teacher preparation. In M. Cochran-Smith, S. Feiman-Nemser, D. J. McIntyre, \& K. E. Demers (Eds.), Handbook of research on teacher education (pp. 269-289). New York: Routledge.

Zwozdiak-Myers, P. (2012). The teacher's reflective practice handbook. London \& New York: Routledge. 